\title{
Regenerative Dentistry: Animal Model for Regenerative Endodontology
}

\author{
Nisarat Ruangsawasdi ${ }^{a}$ b Matthias Zehnder $^{c}$ Raphael Patcas ${ }^{d}$ Chafik Ghayor $^{a}$ \\ Franz E. Weber ${ }^{\text {a }}$ \\ ${ }^{a}$ Oral Biotechnology \& Bioengineering, Cranio-Maxillofacial and Oral Surgery, Center for Dental Medicine, University of Zurich, Zurich, \\ Switzerland: \\ ${ }^{b}$ Department of Pharmacology, Faculty of Dentistry, Mahidol University, Bangkok, Thailand; \\ cPreventive Dentistry, Periodontology, and Cariology, Center for Dental Medicine, University of Zurich, Zurich, Switzerland; \\ dOrthodontics and Pediatric Dentistry, Center for Dental Medicine, University of Zurich, Zurich, Switzerland
}

\section{Keywords}

Endodontics · Regeneration · Animal model · Pulp · Odontoblast · Cell homing

\section{Summary}

Background: Ectopic tissue has been observed frequently in human root canal specimens when cell homing studies were performed at the dorsum of rodents. In contrast, pulp-like tissue formed when immature teeth were implanted on top of the rat calvaria. It was surmised, yet not tested, that the implantation site might affect tissue ingrowth. Methods: Four root sections from human immature molars cleaned with $5 \%$ sodium hypochlorite ( $\mathrm{NaOCl}$ ) followed by $17 \%$ ethylenediaminetetraacetic acid (EDTA) were implanted per rat $(n=5)$. Two specimens were placed at the dorsum (control), while the other two specimens were implanted at the calvaria. After 6 weeks, the specimens were investigated for histological structure, immunoreactivity to dentine sialoprotein (DSP) and bone sialoprotein (BSP), per-area percentage of tissue ingrowth, and gene expression (DSPP, COL1, NGF and VEGF). Data were statistically compared. Results: Tooth specimens placed at the calvaria generally showed pulplike tissue and odontoblast-like cells at the dentinal wall where DSP and BSP immunoreactivity were intense. The area of tissue ingrowth was significantly larger in the specimens placed at the calvaria compared to those placed at the dorsum. DSPP was the only gene that was upregulated significantly when specimens were implanted at the calvaria. Conclusion: Our findings suggest that the calvarial site is superior to the dorsum to study pulp regeneration in human teeth in the rat.

(c) 2016 S. Karger GmbH, Freiburg

\section{Introduction}

An optimal treatment for immature permanent teeth with a necrotic, infected pulp is still elusive. In these cases, root growth is ceased, and the formation of dentin is arrested after the standard endodontic treatment [1]. Poor characteristics of such teeth, i.e. their wide-open apex and large pulp cavity, made them not suitable for mechanical root canal debridement and normal obturation [2]. Traditional root filling materials such as MTA and gutta-percha are also inadequate to strengthen the tooth and promote its growth [2]. In addition, the biting force may cause eventual tooth loss because of hard-tissue fractures in the long term [3]. An alternative treatment has thus been proposed to preserve tooth vitality and to reduce those undesirable outcomes, which has been termed 'pulp regeneration' [4]. The approach has recently been established in clinics to promote pulp tissue regeneration by stem cells from the periapical region of the immature permanent tooth [5]. Instead of filling the root canal with a synthetic material, bleeding is induced for a blood clot to fill the entire canal space and act as a scaffold for regeneration. Radiographic monitoring of healing using this approach showed that the root can continue to grow, yet results are not predictable $[6,7]$. There is a growing number of case reports on drawbacks and unsatisfactory results, such as insufficient bleeding, root calcification, and discoloration of the tooth crown [8].

Multiple alternative approaches based on tissue engineering research have been proposed to regenerate the dental pulp. Among these, so-called cell-free approaches stand a higher chance of being transferrable to clinics [9]. A cell homing method was first introduced to the field of regenerative endodontics by the Mao group [10]. Human teeth were filled with a scaffold material combined with a mix of growth factors and chemokines. The teeth were ectopically placed at the rat dorsum. The newly formed tissue in the root canal showed an irregular pattern. Some studies using this ap-

\section{KARGER}

(c) 2016 S. Karger GmbH, Freiburg

Fax +497614520714 
proach even revealed abundant ectopic tissue type formation in the pulp space such as brown and white adipose tissue $[6,11]$. In addition, the embedding of tooth specimens in the dorsal area showed delayed cell migration and remnants of scaffold material [12]. In contrast, a recent study using a fibrin gel scaffold showed proper pulp structure formation after implanting the immature teeth in the rats on top of the calvaria [13]. The study showed not only the advantages of the fibrin scaffold to home the cells but it also suggested a new animal model to study cell homing for pulp regeneration. The calvarial space may provide a similar microenvironment to that of the tooth socket with various potential cell sources, such as cells from bone and periosteum. It might thus be a better location for implanting teeth than the dorsal area in cell homing studies.

Therefore, we aimed to investigate the effects of the implantation site in an animal model for pulp regeneration. Pulp-like tissue formation in teeth placed on top of the calvarial bone of the rat was compared to that obtained in a control procedure at the dorsal area.

\section{Material and Methods}

\section{Experimental Teeth}

Human immature third molars $(n=20)$ with open root apices supplied by the Center of Dental Medicine, University of Zurich, were used for the current experiments. Ten teeth were taken for histology, and the others were used for gene analysis. Written informed consent was obtained from all donors according to the recommendation of the Swiss Academy of Medical Science [14]. All these teeth were extracted for reasons not related to this study and stored in $0.1 \%$ Thymol at $4{ }^{\circ} \mathrm{C}$. Personnel handling the teeth applied all necessary precautions for infection control. Ethical guidelines were followed [15], and anonymization was performed in accordance with state and federal law [16].

\section{Preparation of Teeth and Root Canals}

Soft tissue remnants at outer root surface were removed using a curette. The teeth were disinfected in $5 \%$ sodium hypochlorite $(\mathrm{NaOCl})$ for $5 \mathrm{~min}$ in an ultrasonic bath (TEC-25, Benzer Dental AG, Zurich, Switzerland) at $60 \mathrm{~W}$ and 33 $\mathrm{Hz}$. Roots were standardized to a length of $3 \pm 1 \mathrm{~mm}$ by selecting the immature teeth with $2-\mathrm{mm}$ root length and cutting the crown $1 \mathrm{~mm}$ above the cementoenamel junction using a diamond-coated disc under water cooling. The pulp tissue was removed using a barbed broach (Dentsply Maillefer, Ballaigues, Switzerland). No further mechanical treatments were performed. Root canals were ultrasonically cleaned with $5 \mathrm{ml}$ of a laboratory-grade $5 \% \mathrm{NaOCl}$ solution for 5 min in an ultrasonic bath. Subsequently, $5 \mathrm{ml}$ of a $17 \%$ ethylenediaminetetraacetic acid (EDTA) solution (Kantonsapotheke, Zurich, Switzerland) was applied for $5 \mathrm{~min}$. All root canals were finally immersed in $5 \mathrm{ml}$ of a normal $(0.9 \%)$ saline solution for $5 \mathrm{~min}$. Teeth were kept sterile in $70 \%$ ethanol in a safety cabinet at room temperature until implantation.

\section{Fibrin Gel Preparation and Placement}

One day before the implantation, teeth were placed under the sterile bench to allow the evaporation of the $70 \%$ ethanol overnight. Subsequently, a $0.3 \%$ fibrin gel was prepared and injected into the root canals before implantation of the tooth specimens in the rats, as described previously [13]. Frozen human fibrin and thrombin dilution prepared from a Tissee ${ }^{\circledR}$ kit (Baxter, Zurich, Switzerland) were suspended in Tris-buffered saline solution at a $\mathrm{pH}$ of 7.4 to form a fibrin gel. The final gel was formed by mixing $8 \mathrm{mg} / \mathrm{ml}$ fibrinogen, $2.5 \mathrm{mmol} / \mathrm{l}$ $\mathrm{Ca}^{2+}$, and $2 \mathrm{U} / \mathrm{ml}$ National Institutes of Health thrombin. Specimens were grouped to 4 teeth per rat with similar size of the pulp space. Two teeth were placed on top of calvarial bone, while the others were implanted at the dorsum. The gel was injected from a sterile syringe into the pulp space using a $26-\mathrm{G}$ can- nula (B. Braun Medical, Crissier, Switzerland). Subsequently, the specimens were stored in a humid sterile chamber at $37^{\circ} \mathrm{C}$ until implantation, which was performed within $2 \mathrm{~h}$.

\section{Implantation}

Five Sprague Dawley rats (200-250 g) were used for these experiments. The following procedures were approved by the institutional ethics committee for animal research. The rats were anesthetized with ketamine and maintained with isoflurane/oxygen during the operation. A longitudinal incision was performed using a scalpel. The blunt end of surgical scissors was then used to dissect the underlying tissue and create space for the tooth specimens. Two tooth specimens were placed subcutaneously in the rats on top of the calvaria. The other two teeth with similar size were surgically placed in the subcutaneous space at the dorsum (fig. 1). Primary wound closure was performed using a surgical staple (3M Health Care, Rueschlikon, Switzerland).

\section{Assessment of Tissue Ingrowth}

Rats were euthanized 6 weeks after implantation in a $\mathrm{CO}_{2}$ chamber. The tooth specimens were explanted and immediately fixed in $4 \%$ paraformaldehyde. Specimens were dehydrated and embedded in Technovit ${ }^{\circledR} 9100 \mathrm{New}$ (Heraeus Kulzer, Wehrheim, Germany) at $-2{ }^{\circ} \mathrm{C}$ according to the manufacturer's instruction. The resin blocks were longitudinally cut at the middle of root canal in mesiodistal plane prior to sectioning $0.5-\mu \mathrm{m}$-thick slides with a microtome (Leica Microsystem, Heerbrugg, Switzerland). Five subsequent sections were prepared from the center of each specimen, of which three sections were used for histological analysis and assessment of tissue ingrowth. The other two sections were kept for immunohistochemical staining. The slides were stained with Goldner's Trichrome, and the images of them were taken using a slide scanner (Zeiss, Feldbach, Switzerland). Quantitative analysis was performed using freely available software (Image J; National Institutes of Health, Bethesda, MD, USA). The areas of ingrown tissue were normalized to the total pulp space area and averaged the 3 sections per specimen, and mean values per specimens were used for the statistical comparison between groups (see below).

\section{Immunohistochemistry}

Immunohistochemical localizations of bone sialoprotein (BSP) and dentin sialoprotein (DSP) were observed in additional serial sections from the center of the specimens. Histologic slides were prepared as mentioned in the previous study [13] and incubated with primary antibodies (Merck Millipore, Darmstadt, Germany) against BSP $(1: 200)$ at $4{ }^{\circ} \mathrm{C}$ overnight and DSP $(1: 100)$ at room temperature for 5 h. 3,3'-diaminobenzidine tetrahydrochloride was used to detect the immunoreactivity of both markers. Slides were counterstained with hematoxylin and observed under light microscopy.

\section{RNA Isolation from Fresh Tissue}

Total RNA was isolated from cells in the tooth specimens stabilized in RNAlater ${ }^{\circledR}$ solution (Qiagen, Hilden, Germany). The ingrown tissue was removed from the root canal using a pin-pointed forceps, and the dentinal wall was scraped to take out the odontoblast-like cell layer using a sharp curette. Cells from both areas were processed separately according to the protocol supplied with the TRIzol ${ }^{\circledR}$ reagent (Life Technology, Luzern, Switzerland). To purify RNA, the silica-membrane from RNeasy ${ }^{\circledR}$ mini kit (Qiagen) was used in accordance to manufacturer's instruction. Quantity and purity of the RNA was determined using NanoDrop ${ }^{\circledR}$ ND-1000 spectrophotometer (Witec AG, Littau, Switzerland) and ethidium bromide-visualizing agarose gel, respectively.

\section{Real-Time RT-PCR}

Two-step real time RT-PCR was used for DNA quantification. $200 \mathrm{ng}$ of total isolated RNA was reverse-transcribed into cDNA using a cDNA synthesis kit (Roche, Basel, Switzerland). The master mix was prepared following the manufacturer's instruction. Real-time PCR was performed using the LightCycler $^{\circledR} 480$ DNA SYBR Green I master (Roche). For the normalized expression, the rat-specific forward $(\mathrm{F})$ and reverse (R) primers including DSPP, VEGF, NGF, and COL I were used in this experiment, and GAPDH was the house- 
Fig. 1. Endodontically treated tooth specimens placed in subcutaneous space on top of calvaria and at dorsum of the rats. Surgical placement was performed in the same rat at calvaria (A) and at dorsum (B). 6 weeks embedding showed a fibrous layer that encapsulated the tooth specimens (arrow, C). Newly formed tissue of tooth specimens placed at the calvaria is illustrated in D-I. Overview of the regenerated tissue located in the root canal (D). Inner regenerated tissue showed revascularization and innervation (E). The tissue structure was arranged into 4 layers as normal pulp tissue $(\mathbf{F})$ including central pulp (cp), cellrich zone (cr) and cellfree zone (cf) and apparent odontoblast cell layer (odl). Newly formed tubular dentine $(\nabla)$ was observed at the dentinal wall underneath odontoblastlike cells (G). Immu-
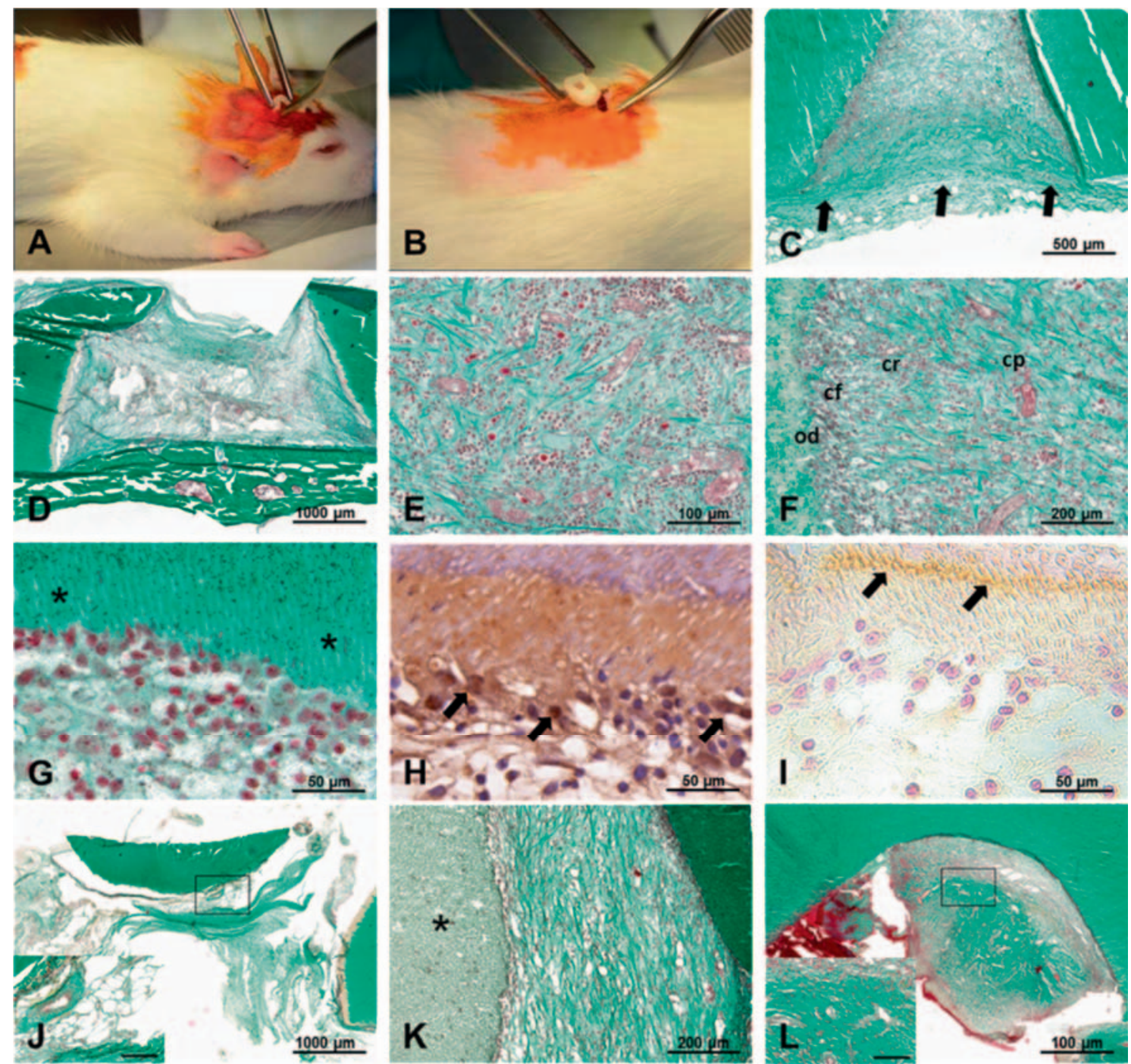

nohistochemical analysis revealed BSP $(\mathbf{H})$ and DSP $(\mathbf{I})$ in the area indicated with bold arrow. The regenerated tissue in tooth specimens placed at dorsum is presented in $\mathbf{J}$-L. Low magnification image shows the irregular type of newly formed tissue (J). Adipose tissue (enlarged image in $\mathbf{J}$ ), fibrin gel remnants $(\mathbf{L})$ and dense collagenous tissue (L) were observed in the root canal. The histological slides were prepared from resin embedding block and stained with Goldner's Trichrome.

keeping gene to normalize for internal gene expression. The $25 \mu \mathrm{l}$ of master mix briefly consisted of $2 \mu \mathrm{l}$ of cDNA and $0.3 \mu \mathrm{mol} / \mathrm{l}$ of primer. Relative gene expression was analyzed using the $2^{-\Delta \Delta C t}$ method as previously reported [17].

\section{Statistics}

Non-parametric method was used to compare the area of tissue ingrowth between two groups (Mann-Whitney U test), whereas parametric methods were used in comparison of gene expression regarding the normally distributed data (Shapiro-Wilk test). The difference in gene expression was thus tested with oneway analysis of variance (ANOVA) followed by Tukey's HSD for multiple comparisons. The significance level was set at $5 \%(\mathrm{p}<0.05)$.

\section{Results}

\section{Histologic Analysis}

Histologic analysis after transplanting the tooth sections for 6 weeks revealed that all specimens were filled with dense fibrous connective tissue and contained a newly formed tissue (fig. 1C). In the tooth placed on top of calvarias, more than half of root canal was occupied with a highly vascularized and innervated connective soft tissue (fig. 1D, E). The regenerated tissue also showed the typical cell layers of a dental pulp (fig. 1F). At the dentinal wall, odontoblast-like cells were found in intimate contact with dentin and were positive to BSP, a marker for odontoblast function (fig. 1G, $H)$. Regenerated dentin was also observed underneath odontoblast-like cells (* in fig. 1G) and showed DSP immunoreactivity along the dentinal wall at the interface between new dentin and old dentin (fig. 1I). In contrast, the transplanting of tooth specimens to the dorsum showed various types of ingrown tissue (fig. 1J) and remnants of the fibrin gel originally contained in the root canal space (fig. $1 \mathrm{~K}$ ). The local cells were attracted into the root canal and then formed a mixture of tissue types, including fatty tissue with vacuoles (fig. 1J) and dense collagenous tissue (fig. 1L). 


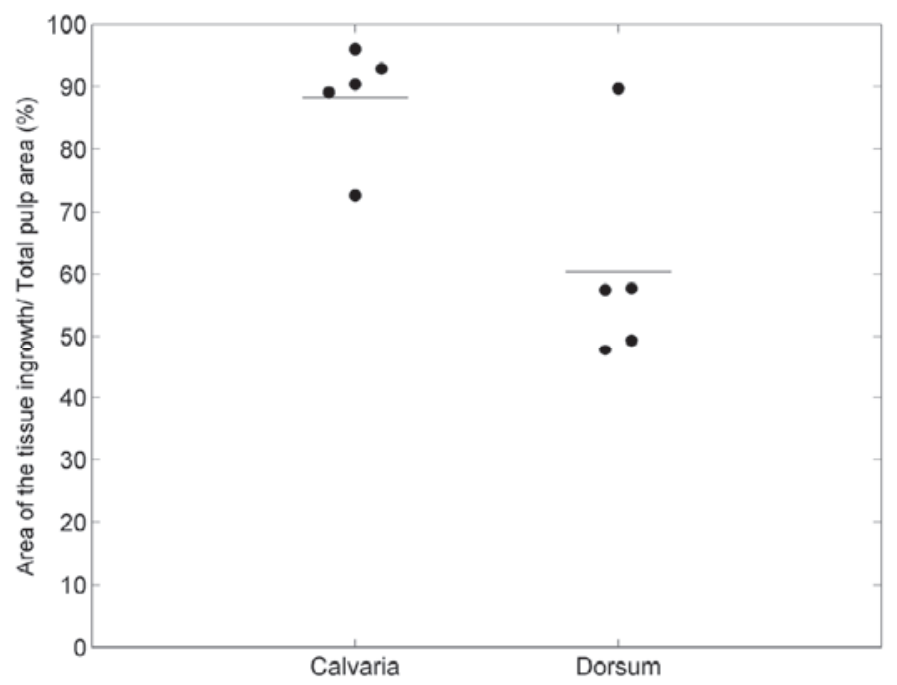

Fig. 2. Specimens placed on top of calvaria showed greater area of tissue ingrowth. 3-mm tooth sections were implanted in the subcutaneous area at the dorsum and on top of calvaria for 6 weeks. Histomorphometric analysis with image J was used to quantify the area of the tissue ingrowth and the total pulp space. Statistical analysis showed that area of tissue ingrowth in specimens implanted on the calvaria was significantly higher than in counterparts implanted at the dorsum $\left({ }^{*} \mathrm{p}<0.05\right)$. Dot $(\cdot)$ indicates averaged value from each specimen. Line (-) indicates median value and interquartile range of the group.

\section{Tissue Ingrowth Analysis}

Comparison of the ingrowth related to the total pulp area showed a significant difference between two embedding sites $(\mathrm{p}<$ 0.05 , fig. 2). The percent of tissue ingrowth in the tooth specimens from calvarias displayed a median of $90 \%$ (IQR $=80-94 \%$ ), while the tooth specimens from dorsum showed a median of $57 \%$ (IQR = 49-74\%). Accordingly, the histological measurement showed better cell migration and tissue formation at the calvarial area compared to that of the dorsum.

\section{Gene Expression Analysis}

Gene expression of the different implantation sites was evaluated by the normalized gene expression in cells from two areas; cells contacted to the dentinal wall and from the bulk tissue. After analyzing 6 specimens from each area, DSPP gene expression levels were significantly $(\mathrm{p}<0.05)$ higher in the specimens placed on top of the calvaria compared to counterparts from the dorsum. The $D S P P$ gene was also up-regulated in cells from the dentinal wall compared to cells from the inner regenerated tissue of the calvarial specimens (fig. 3). On the other hand, the expression of COL I, $N G F$, and VEGF did not differ between the two implantation sites.

\section{Discussion}

In this study, we tested a novel site for implanting tooth specimens for cell homing studies in rodents. Apparently, rat calvarias offer a more suitable cell population and optimized conditions for the formation of pulp-like tissue than dorsal tissues in these animals.

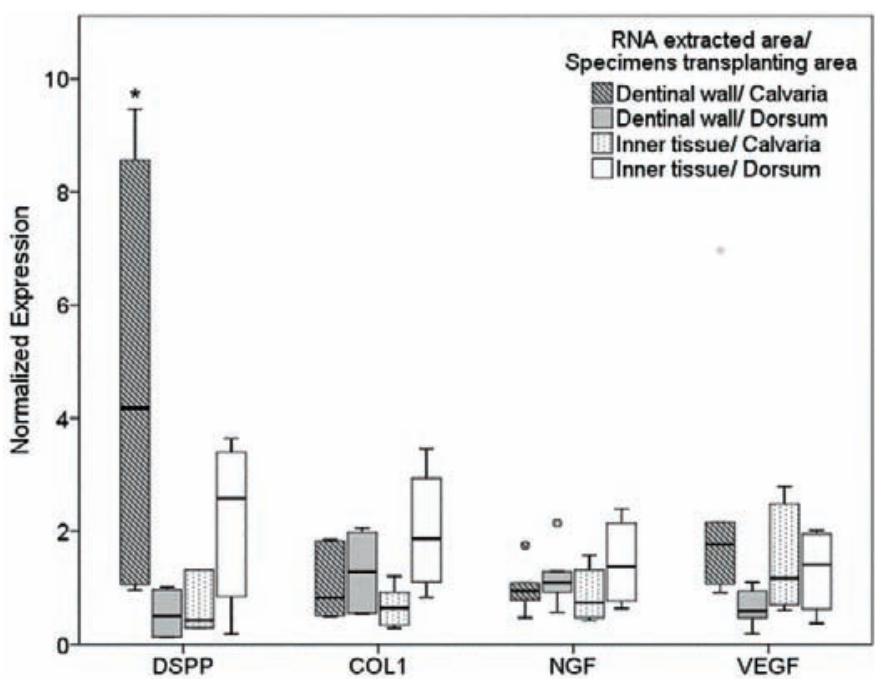

Fig. 3. $D S P P$ gene expression was highly up-regulated at the dentinal wall of specimens implanted at the calvaria for 6 weeks. Four genes, DSPP, COL1, NGF and $V E G F$ were analyzed regarding their expression level in specimens placed at the calvaria and the dorsum. Cells at dentinal wall of the teeth at the calvaria up-regulated the DSPP gene significantly compared to cells at the dentinal wall of dorsal specimens, or cells from the inner regenerated tissue of calvarial specimens $\left({ }^{*} \mathrm{p}<0.05\right)$.

Our study is limited by the fact that it remains to be shown to which extent the implanting area and the tooth preparation methods mentioned in this context are translational to clinical application. The length of specimens used in this study was shorter than the distance for cell migration under clinical conditions. It has also been argued that for pulpal regeneration, the apical papilla of immature teeth plays a key role [18]. Consequently, immunosuppressed rodents were used to be able to implant human teeth with the cells from the apical papilla [19]. However, from a clinical standpoint, it remains unclear to which extent the apical papilla is still present in teeth with long-standing apical lesions. Furthermore, from a general health perspective, the time and money spent on pulp regeneration studies can only be justified if regenerative concepts can eventually be extrapolated to mature teeth. In mature teeth, there is no apical papilla, and pluripotent cells have to be recruited from the blood stream or the periapical area [20]. In this context, the current animal model may be more relevant than previously described simulations.

The current animal model, implanting endodontically prepared tooth specimens on top of calvarias, resulted in apparent aspects of true regeneration of pulp-like tissue rather than reparation. Recent reports have raised concern that a cell-free approach might yield a sequence of wound healing instead of regeneration [7, 21]. However, our results showed connective tissue revitalized with blood vessels and peripheral nerve-containing tissue, which was histologically rather similar to normal dental pulp tissue. This ingrown tissue contained odontoblast-like cells integrating into dentinal tubules. The area underneath these cells appeared to be re-mineralized, and also showed positive immunoreactivity to rat anti-DSP 
and BSP. The cytoplasmic processes could not be observed in all the odontoblast-like cells. These distortions can be accounted for by the sectioning technique and the spatial limitation of light microscopy. The percent of tissue ingrowth has been noted higher in this study, although it was conducted in a shorter duration than our previous experiment [13]. This was most likely due to the size of specimens. Additionally, gene analysis showed up-regulation of DSPP at the root canal wall, which is the expected location [22], while the other genes were not different. This result of gene analysis is also in accordance with the histological image where the mineral matrix was found to be matured. In contrast, specimens implanted at the dorsum of animals showed a different pattern of gene expression. Instead of pulp connective tissue, dense fibrous tissue or ectopic mineralized tissue was found in the root canal space. Although the dorsal space is the ideal spot in the rodent to implant a maximum amount of tooth specimens, placing the tooth in proximity to calvaria appears to yield an experimental environment that is superior to study cell homing in regenerative endodontics.

In addition, this current animal model was performed in rats while the other studies used a mouse model [10-12, 19]. Mice are the primary animal used for many scientific tests because they are inexpensive and easy to manipulate in the laboratory. For a primary screening of biomaterials and stem cell response, the previous studies in the field of regenerative endodontics have chosen mice $[10-12,19]$. However, rats were used here to investigate whether the tissue remained growing into the human pulp space. Although rats and mice are close species, rats have biology and physiology more similar to the corresponding human condition. They also feature a larger body, which was necessary for the current comparative study [23].

An interesting finding was that in the immature permanent tooth a vital pulp-like tissue grew without implantation of stem cells. The different tissue types formed in the root canal reveal distinct cell sources between the calvarial and the dorsal area. Although tooth specimens were similarly placed in the subcutaneous space in both areas, the supracalvarial space apparently contains cells that can form dental pulp-like tissue, which was already shown in our previous study [13]. Cells residing in the periosteum appear to be the source for this approach. These cells have been studied extensively, and their regenerative potential is used in multiple applications [24]. Periosteum-derived progenitor cells feature multi-differentiation potency and the ability to proliferate rapidly. They are the reservoir for bone regeneration and exhibit a profile similar to fibroblasts [25], and they share the characteristics of pluripotent cells with other oral stem cell niches including dental pulp stem cells, the stem cells of apical papilla, and periodontal ligament-derived stem cells [26]. Especially, the periodontal ligament surrounding the tooth has been claimed to express an extracellular matrix protein, periostin, similar to the periosteum [27]. It would appear that the spatial conditions of teeth in jawbone are similar to those at the calvaria. Nevertheless, further investigation of the in volved cell population should be performed to better understand the current animal model.
It should be noted that the formation of pulp-like tissue in the root canal space is not only influenced by the location of implantation but also by chemical conditioning of the canal wall. EDTA irrigation can help to promote a functional pulp by the liberation of TGF- $\beta$ and other important growth factors from the mineralized aspect of the root dentin [12, 13, 28-32]. Irregular tissue formation has been reported in pulp regeneration when mere $\mathrm{NaOCl}$ was used to clean in the root canal $[7,21]$. NaOCl is necessary for disinfection and the dissolution of necrotic pulp tissue remnants [33, 34]; however, it has adverse effects on physical tooth properties and deproteinizes the dentin surface $[28,35,36]$. On the other hand, EDTA can preserve the vitality of stem cells, and promotes differentiation of dental pulp stem cells cultured on dentin discs $[12,28]$. Obviously, the irrigation of EDTA as used in this study converts the immature tooth to be a bioactive scaffold.

We filled the canal space with fibrin gel, which acts as a scaffold for immigrating cells [37]. The selection of the scaffold in the cleaned and disinfected pulp space is also considered to be essential for the success of tissue engineering in the current context $[8,11$, 38]. Fibrin gel appears to closely mimic a blood clot, without the inherent propensity of the latter to discolor the tooth. It is a material that can be modified easily to suit the application and has been approved by Food and Drug Administration [39]. Compared to other hydrogels it shows better results in cell proliferation and differentiation [40]. The modified concentration of fibrinogen in the gel also enhances cell reactions [37]. As in the current study, we used the minimal fibrinogen concentration in an attempt to prevent cells from forming ectopic tissues in the root canal. Apparently, the fibrin in its current composition fulfills many criteria of an ideal scaffold for pulp regeneration. The translation of this gel to clinics, however, still requires modifications, such as opacity for radiographic monitoring of placement, gelation time, and other factors that might affect a convenient and safe application.

\section{Conclusion}

A proper cell source in the calvarial area, a supportive tooth preparation method, and a suitable scaffold in the pulp space appear to be a promising and relevant strategy to study cell homing during pulp regeneration. Using the current approach, more studies can now be done to further regenerative endodontics and finally translate it into clinics.

\section{Acknowledgements}

The authors would like to thank Yvonne Bloemhard and Alexandr Tchouboukov for technical assistance and Flora Nichols and Dr. Thea Fleischman for support for the animal trials.

\section{Source of Funding}

This research was supported by Swiss Government Scholarship and the re- 
search grant from Swiss Dental Association, Switzerland (SSO, project number 270-13). The histological support was from center for microscopy and image analysis (ZMB), University of Zurich.

\section{Disclosure Statement}

None of the authors has a conflict of interest.

\section{Author Contributions}

NR, MZ, RP, CG, FEW: designed research; NR, CG, FEW: performed experiments; NR, MZ, RP, CG, FEW: data analysis and interpretation; NR, MZ, FEW: manuscript drafting; NR, MZ, RP, CG, FEW: revisions and approval.

\section{References}

1 Cvek M: Prognosis of luxated non-vital maxillary incisors treated with calcium hydroxide and filled with gutta-percha. A retrospective clinical study. Endod Dent Traumatol 1992;8:45-55.

$D_{2}$ Andreasen JO, Farik B, Munksgaard EC: Long-term calcium hydroxide as a root canal dressing may increase risk of root fracture. Dent Traumatol 2002;18: 134-137.

3 Andreasen JO, Munksgaard EC, Bakland LK: Comparison of fracture resistance in root canals of immature sheep teeth after filling with calcium hydroxide or MTA. Dent Traumatol 2006;22:154-156.

4 Banchs F, Trope M: Revascularization of immature permanent teeth with apical periodontitis: new treatment protocol? J Endod 2004;30:196-200.

5 Chueh LH, Huang GT: Immature teeth with periradicular periodontitis or abscess undergoing apexogenesis: a paradigm shift. J Endod 2006;32:1205-1213.

6 Wang X, Thibodeau B, Trope M, Lin LM, Huang GT: Histologic characterization of regenerated tissues in canal space after the revitalization/revascularization procedure of immature dog teeth with apical periodontitis. J Endod 2010;36:56-63.

7 Shimizu E, Ricucci D, Albert J, Alobaid AS, Gibbs JL, Huang GT, Lin LM: Clinical, radiographic, and histological observation of a human immature permanent tooth with chronic apical abscess after revitalization treatment. J Endod 2013;39:1078-1083.

8 Nosrat A, Homayounfar N, Oloomi K: Drawbacks and unfavorable outcomes of regenerative endodontic treatments of necrotic immature teeth: a literature review and report of a case. J Endod 2012;38:1428-1434

-9 Mao JJ, Kim SG, Zhou J, Ye L, Cho S, Suzuki T, Fu SY, Yang R, Zhou X: Regenerative endodontics: barriers and strategies for clinical translation. Dent Clin North Am 2012;56:639-649.

10 Kim JY, Xin X, Moioli EK, Chung J, Lee CH, Chen M, Fu SY, Koch PD, Mao JJ: Regeneration of dental- pulplike tissue by chemotaxis-induced cell homing. Tissue Eng Part A 2010;16:3023-3031.

11 Galler KM, Hartgerink JD, Cavender AC, Schmalz G D'Souza RN: A customized self-assembling peptide hydrogel for dental pulp tissue engineering. Tissue Eng Part A 2012;18:176-184.

12 Galler KM, D'Souza RN, Federlin M, Cavender AC, Hartgerink JD, Hecker S, Schmalz G: Dentin conditioning codetermines cell fate in regenerative endodontics. J Endod 2011;37:1536-1541.

13 Ruangsawasdi N, Zehnder M, Weber FE: Fibrin gel improves tissue ingrowth and cell differentiation in human immature premolars implanted in rats. J Endod 2014; $40: 246-250$.
14 Salathe M: Vorlagen für eine «Generaleinwilligung» und für ein Reglement. Schweiz Ärztez 2010;91:761763. www.saez.ch/docs/saez/archiv/de/2010/2010-19/ 2010-19-613.pdf (last accessed August 18, 2016).

15 World Health Organization: Guideline for Obtaining Informed Consent for the Procurement and Use of Human Tissue, Cells and Fluids in Research. 2003. www.who.int/reproductivehealth/topics/ethics/human tissue use_guide serg/en/ (last accessed August 18, 2016)

16 Federal Assembly of the Swiss Confederation. Federal Act on Research involving Human Beings 810.30, 2(2) and 32(3). www.admin.ch/ch/e/rs/8/810.30.en.pdf (last accessed August 18, 2016).

17 Livak KJ, Schmittgen TD: Analysis of relative gene expression data using real-time quantitative PCR and the 2(-Delta Delta C(T)) Method. Methods 2001;25:402-408.

18 Huang GT, Sonoyama W, Liu Y, Liu H, Wang S, Shi S: The hidden treasure in apical papilla: the potential role in pulp/dentin regeneration and bioroot engineering. J Endod 2008;34:645-651.

19 Huang GT, Yamaza T, Shea LD, Djouad F, Kuhn NZ, Tuan RS, Shi S: Stem/progenitor cell-mediated de novo regeneration of dental pulp with newly deposited continuous layer of dentin in an in vivo model. Tissue Eng Part A 2010;16:605-615.

20 Huang GT, Gronthos S, Shi S: Mesenchymal stem cells derived from dental tissues vs. those from other sources: their biology and role in regenerative medicine. J Dent Res 2009;88:792-806.

21 Huang GT, Garcia-Godoy F: Missing concepts in de novo pulp regeneration. J Dent Res 2014;93:717-724.

22 Conde MC, Nedel F, Campos VF, Smith AJ, Nor JE, Demarco FF, Tarquinio SB: Odontoblast RNA stability in different temperature-based protocols for tooth storage. Int Endod J 2012;45:266-272.

23 Lannaccone PM, Jacob HJ: Rats! Dis Model Mech2009; 2:206-210.

24 Arnsdorf EJ, Jones LM, Carter DR, Jacobs CR: The periosteum as a cellular source for functional tissue engineering. Tissue Eng Part A 2009;15:2637-2642

25 Zhu, S.J., Choi, B.H., Huh, J.Y., Jung, J.H., Kim, B.Y., Lee, S.H: A comparative qualitative histological analysis of tissue-engineered bone using bone marrow mesenchymal stem cells, alveolar bone cells, and periosteal cells. Oral Surg Oral Med Oral Pathol Oral Radiol Endod 2006;101:164-169.

26 Ponnaiyan D: Do dental stem cells depict distinct characteristics? - establishing their 'phenotypic fingerprint'. Dent Res J (Isfahan) 2014;11:163-172.

27 Horiuchi K, Amizuka N, Takeshita S, Takamatsu H, Katsuura M, Ozawa H, Toyama Y, Bonewald LF, Kudo A: Identification and characterization of a novel protein, periostin, with restricted expression to periosteum and periodontal ligament and increased expression by transforming growth factor beta. J Bone Miner Res 1999;14:1239-1249.
28 Trevino EG, Patwardhan AN, Henry MA, Perry G, Dybdal-Hargreaves N, Hargreaves KM, Diogenes A: Effect of irrigants on the survival of human stem cells of the apical papilla in a platelet-rich plasma scaffold in human root tips. J Endod 2011;37:1109-1115.

29 Martin DE, De Almeida JF, Henry MA, Khaing ZZ, Schmidt CE, Teixeira FB, Diogenes A: Concentrationdependent effect of sodium hypochlorite on stem cells of apical papilla survival and differentiation. J Endod 2014;40:51-55.

30 Zhao S, Sloan AJ, Murray PE, Lumley PJ, Smith AJ: Ultrastructural localisation of TGF-beta exposure in dentine by chemical treatment. Histochem J 2000;32:489494.

31 Galler KM, Buchalla W, Hiller KA, Federlin M, Eidt A, Schiefersteiner M, Schmalz G: Influence of root canal disinfectants on growth factor release from dentin. J Endod 2015;41:363-368.

32 Galler KM, Widbiller M, Buchalla W, Eidt A, Hiller KA, Hoffer PC, Schmalz G: EDTA conditioning of dentine promotes adhesion, migration and differentiation of dental pulp stem cells. Int Endod J 2016;49: 581-590.

33 Thibodeau B, Teixeira F, Yamauchi M, Caplan DJ, Trope M: Pulp revascularization of immature dog teeth with apical periodontitis. J Endod 2007;33:680-689.

34 Zehnder M: Root canal irrigants. J Endod 2006;32: 389-398.

35 Ragnarsson KT, Rechenberg DK, Attin T, Zehnder M: Available chlorine consumption from $\mathrm{NaOCl}$ solutions passively placed in instrumented human root canals. Int Endod J 2015;48:435-440.

36 Marending M, Paque F, Fischer J, Zehnder M: Impact of irrigant sequence on mechanical properties of human root dentin. J Endod 2007;33:1325-1328.

37 Catelas I, Sese N, Wu BM, Dunn JC, Helgerson S, Tawil B: Human mesenchymal stem cell proliferation and osteogenic differentiation in fibrin gels in vitro. Tissue Eng 2006; 12:2385-2396

38 Galler KM, D’Souza RN, Hartgerink JD, Schmalz G: Scaffolds for dental pulp tissue engineering. Adv Dent Res 2011;23:333-339.

39 Jung RE, Schmoekel HG, Zwahlen R, Kokovic V Hammerle $\mathrm{CH}$, Weber FE: Platelet-rich plasma and fibrin as delivery systems for recombinant human bone morphogenetic protein-2. Clin Oral Implants Res 2005; $16: 676-682$.

40 Hermeto LC, Rossi R, Padua SB, Pontes ER, Santana AE: Comparative study between fibrin glue and platelet rich plasma in dogs skin grafts. Acta Cir Bras 2012; 27:789-794. 